\title{
Expression of different survivin variants in gastric carcinomas: first clues to a role of survivin-2B in tumour progression
}

\author{
A Krieg', C Mahotka', T Krieg', H Grabsch', W Müller', S Takeno', CV Suschek², M Heydthausen³, \\ HE Gabbert' and CD Gerharz**,
}

'Institute of Pathology, Heinrich Heine-University, Moorenstr 5, D-40225, Duesseldorf, Germany; ${ }^{2}$ Institute of Immunobiology, Heinrich Heine-University, Moorenstr 5, D-40225, Duesseldorf, Germany; ${ }^{3}$ Center for Applied Medical Informatics, Heinrich Heine-University, Moorenstr 5, D-40225, Duesseldorf,

Germany

\begin{abstract}
Survivin is a novel member of the inhibitor of apoptosis family and determines the susceptibility of tumour cells to proapoptotic stimuli. Recently, we identified two novel alternative splice variants of survivin, differing in their anti-apoptotic properties: whereas the anti-apoptotic potential of survivin- $\Delta \mathrm{E} \times 3$ is preserved, survivin- $2 \mathrm{~B}$ has lost its anti-apoptotic potential and may act as a naturally occurring antagonist of survivin. Because the in vivo expression of these alternative splice variants has not been explored so far, we analysed gastric carcinomas of different histological subtypes, grades and stages. Since no antibodies are currently available to determine the novel splice variants, quantitative reverse transcriptase polymerase chain reaction was performed, using RNA samples obtained from 30 different gastric carcinomas. Polymerase chain reactions products were quantified by densitometric evaluation. We found that all gastric carcinomas, irrespective of their histological types, grades or stages, express survivin- $\Delta \mathrm{E} \times 3$, survivin-2B and survivin, the latter being the dominant transcript. Comparing the disease stages $I+\|$ with $I I+I \mathrm{I}$, expression of survivin and survivin $-\Delta \mathrm{E} \times 3$ remained unchanged. In contrast, a significant $(P=0.033)$ stage-dependent decrease in the expression of survivin-2B became evident. Our study demonstrates for the first time the expression of alternative splice variants in gastric carcinomas and provides a first clue to a role of survivin- $2 \mathrm{~B}$ in tumour progression.

British Journal of Cancer (2002) 86, 737-743. DOI: 10.1038/sj/bjc/6600I53 www.bjcancer.com

(c) 2002 Cancer Research UK
\end{abstract}

Keywords: alternative splicing; apoptosis; IAPs; RT-PCR; survivin

Increasing resistance to programmed cell death by an imbalance between pro-apoptotic and anti-apoptotic proteins plays a critical role during tumorigenesis and tumour progression, facilitating the accumulation of transforming mutations and promoting evasion of tumour cells from immunosurveillance (Rudin and Thompson, 1997). A number of gene products with anti-apoptotic potential is known to modulate tumour cell viability and resistance to programmed cell death (Thompson, 1995; Chao and Korsmeyer, 1998; Fadeel et al, 2000). Recently, the inhibitor of apoptosis protein (IAP) family has been identified that is characterised by one or multiple domains designated as baculoviral IAP repeats (BIRs) (Crook et al, 1993; LaCasse et al, 1998). The BIR domain is considered to be essential for the anti-apoptotic potential of IAPs, which - inter alia - directly bind and inhibit terminal effector caspases (Roy et al, 1997; Deveraux and Reed, 1999).

Survivin was identified as a structurally unique member of the IAP family that contains only a single BIR domain (Ambrosini et al, 1997). Acting at the interface between apoptosis and mitosis, survivin was shown to be both a chromosomal passenger protein (Skoufias et al, 2000) and to prevent programmed cell death by inhibiting the actions of caspase-3 and caspase-7 (Tamm et al, 1998; Shin et al, 2001). Expression of survivin was found in prolif-

*Correspondence: CD Gerharz; E-mail: gerharz@med.uni-duesseldorf.de Received 23 August 200I; revised II December 200I; accepted 17 December 2001 erating foetal tissues, but not in most differentiated adult tissues (Ambrosini et al, 1997). Remarkably, increased survivin expression was observed in the most common human neoplasms, including oesophageal cancer, gastric cancer, colorectal carcinoma, non-small cell lung cancer, bladder cancer, neuroblastoma and lymphoma (Adida et al, 1998, 2000; Kawasaki et al, 1998; Lu et al, 1998; Monzo et al, 1999; Swana et al, 1999; Sarela et al, 2000; Kato et al, 2001). Expression of survivin may enhance tumour cell viability during tumour progression and enable the neoplastic cells to overcome the cytotoxic effects of anticancer drugs. As recently shown by our group (Mahotka et al, 1999), two novel alternatively spliced survivin variants, i.e. survivin- $\Delta \mathrm{Ex} 3$ and survivin- $2 \mathrm{~B}$, may be relevant for the fine tuning of survivin actions: survivin- $\Delta \mathrm{Ex} 3$, which lacks exon 3, exhibits pronounced anti-apoptotic activity, whereas survivin-2B, which contains a part of intron 2 as an additional cryptic exon, has largely lost its anti-apoptotic activity. Survivin variants have also been detected in other species in the meantime (Conway et al, 2000; Wenzel et al, 2000), suggesting an evolutionarily conserved mechanism for the regulation of survivin actions by alternative splicing.

Whereas expression of survivin has previously been observed in gastric cancer ( $L u$ et al, 1998), no data are available so far on the role of survivin- $\Delta \mathrm{Ex} 3$ and survivin- $2 \mathrm{~B}$ in this cancer type. Therefore, we quantified the expression levels of the different survivin variants in a panel of 30 gastric carcinomas. Because no antibodies are currently available that discriminate between the different survivin variants on the protein level, we used a survivin-specific 
reverse transcriptase polymerase chain reaction (RT-PCR) for our analysis. This study provided first ex vivo evidence for a role of survivin-2B in the progression of gastric cancer.

\section{MATERIALS AND METHODS}

\section{Patients and specimens}

Tissue samples of 30 consecutive gastric carcinomas were obtained from patients who had undergone gastrectomy. The tumour specimens were immediately flash frozen in liquid nitrogen and stored at $-80^{\circ} \mathrm{C}$ until total RNA extraction or protein isolation was performed. Tumour typing, grading and staging were performed according to the principles outlined by the WHO (Watanabe et al, 1998) and the UICC (Sobin and Wittekind, 1997). Additional clinicopathological parameters such as age, sex, lymphatic vessel invasion, blood vessel invasion, Helicobacter pylori colonisation and density of the chronic inflammatory cell infiltration in the tumour-adjacent normal gastric mucosa (according to the Sydney System (Dixon et al, 1996)) were defined for all patients.

\section{RNA - extraction}

Total RNA of the tumours and paired non-neoplastic tissue samples was isolated by acid guanidium thiocyanate phenol chloroform extraction with minor modifications as previously described (Chomczynski and Sacchi, 1987).

\section{Reverse transcription and polymerase chain reaction}

Total RNA ( $2 \mu \mathrm{g})$ was reversely transcribed in a final $30 \mu \mathrm{l}$ reaction volume using $5 \mathrm{U}$ AMV reverse transcriptase (Promega, Heidelberg, Germany), $1 \times$ RT buffer (Promega), $20 \mathrm{U}$ of RNase inhibitor RNAsin (Promega), $25 \mu \mathrm{M}$ of each deoxynucleotide triphosphate (Qiagen, Hilden, Germany) and 10 pmol of each sequence-specific RT primer. Because survivin mRNA has to be distinguished from effector cell protease receptor-1 (EPR-1) mRNA, a naturally occurring antisense-mRNA of survivin which might bias survivin amplification (Zaman and Conway, 2000), we used the primer 5'-AGG AAC CTG CAG CTC AGA-3', corresponding to nucleotides $914-931$ of the survivin antisense strand (accession no NM_001168). For GAPDH-specific cDNA synthesis, the antisense primer 5'-CTC CTG GAA GAT GGT GAT GG-3', corresponding to nucleotides 251-270 of the GAPDH antisense strand (accession no J04038) was used. Reverse transcription of survivin and GAPDH was performed in the same reaction to avoid variations in efficiency of cDNA synthesis. The specific RT reaction mixtures were incubated at $50^{\circ} \mathrm{C}$ for $1 \mathrm{~h}$. PCR amplification was performed in a final volume of $50 \mu \mathrm{l}$ containing $3 \mu \mathrm{l}$ first strand cDNA solution, $2.5 \mathrm{U}$ of Taq polymerase, $1 \times$ PCR-buffer, $10 \mu \mathrm{l}$ Q-solution (except GAPDH amplification), $25 \mu \mathrm{M}$ of each dNTP (all Qiagen) and 25 pmol of each $3^{\prime}$ and $5^{\prime}$ sequence specific oligonucleotide primer.

To determine the saturation phase of RT-PCR amplification, we started with a cycle titration for survivin and GAPDH. Reactions were stopped after 15,20, 25, 30, 35 and 40 cycles, and the PCR products of the different cycle numbers were electrophoresed on $3 \%$ agarose gels containing ethidium bromide. The signal intensity of amplification products was quantified by densitometry as described below. PCR was then performed for all cDNA samples with 35 (survivin) or 25 cycles (GAPDH), which did not reach the saturation phase and permitted the densitometric quantification and comparison of amplification product levels.

Survivin-PCR amplification was performed on a PTC-100 Thermal controller (Biozym Diagnostic, Hess, Oldendorf, Germany) with initial denaturation at $95^{\circ} \mathrm{C}$ for $2 \mathrm{~min}$, followed by 35 cycles of denaturation at $94^{\circ} \mathrm{C}$ for $30 \mathrm{~s}$, annealing for $1 \mathrm{~min}$ at $58^{\circ} \mathrm{C}$, extension at $72^{\circ} \mathrm{C}$ for $1 \mathrm{~min}$ and a final extension at $72^{\circ} \mathrm{C}$ for
5 min. GAPDH - PCR amplification conditions were identical to those described above except annealing at $64^{\circ} \mathrm{C}$ and 25 cycles. Primers were designed to amplify the entire coding region of survivin: 5'-GCA TGG GTG CCC CGA CGT TG-3' (forward; corresponding to position $48-67$ of the survivin mRNA; accession no NM_001168) and 5'-GCT CCG GCC AGA GGC CTC AA-3' (reverse). RT - PCR for GAPDH as a constitutively expressed gene was performed using the primers 5'-ACG GAT TTG GTC GTA TTG GGC G-3' (forward; corresponding to position 59-80; accession no J04038) and 5'-CTC CTG GAA GAT GGT GAT GG-3' (reverse). PCR products were electrophoresed on 3\% agarose gels containing ethidium bromide and visualised under UV-transillumination.

All RT-PCR amplifications were carried out in duplicate to confirm reproducibility. To ensure that amplification of survivin and GAPDH was specific, PCR bands were excised from agarose gels and isolated using the QIAquick gel extraction kit (Qiagen). The purified PCR-products were sequenced using the ABI-Prism BigDye Terminator Cycle Sequencing Kit (Applied Biosystems, Weiterstadt, Germany) and the oligonucleotides designed for PCR amplification. Sequence analysis was performed with a ABIPrism 310 sequencer (Applied Biosystems).

\section{Quantification of PCR - products and statistical analysis}

Electrophoresed and ethidium bromide stained PCR products from two independent RT-PCR reactions were recorded under UVtransillumination by the Gel-Doc 1000 apparatus (Bio-Rad, München, Germany) and quantified by densitometric evaluation of signal intensity using the Kodak Digital Science 1D software. GAPDH mRNA levels were used to normalise the mRNA levels of the different survivin variants, calculating relative mRNA levels as the ratios between survivin variants and GAPDH.

\section{Immunoblotting}

Protein extracts from four arbitrarily selected gastric carcinomas were isolated by disrupting flash frozen tissue samples in lysis buffer $(100 \mathrm{~mm} \mathrm{NaCl}, 10 \mathrm{~mm}$ Tris- $\mathrm{HCl}$ pH 7.6, $1 \mathrm{~mm}$ EDTA $\mathrm{pH} 8, \quad 1 \% \quad \mathrm{NP} 40$ and protease-inhibitor). Protein aliquots $(100 \mu \mathrm{g})$ were electrophoresed through $15 \%$ SDS-polyacrylamide gels at $70 \mathrm{~mA}$ for $4 \mathrm{~h}$. Blotting to Optitran BA-S85 nitrocellulose membranes (Schleicher \& Schuell, Dassel, Germany) was performed for $1.5 \mathrm{~h}$ at $650 \mathrm{~mA}$ in a tank of transfer buffer pH 8.3 (25 mM Tris-HCl, $192 \mathrm{~mm}$ Glycin, 20\% Methanol) using the Hoefer TE series Transphor electrophoresis Unit (Hoefer Scientific instruments, San Francisco, CA, USA). To verify transfer efficiency and protein integrity, nitrocellulose membranes were stained with Ponceau S $0.2 \%$. The membranes were blocked over night in blocking buffer ( $100 \mathrm{~mm}$ Tis- $\mathrm{HCl}, \mathrm{pH} 7.5,150 \mathrm{mM} \mathrm{NaCl}$, $0,2 \%$ Tween 20 ) plus $3 \%$ non-fat dry milk and $1 \%$ BSA, incubated for $2 \mathrm{~h}$ at room temperature with the polyclonal rabbit anti-human survivin antibody SURV 11-A (Alpha Diagnostic International Inc, San Antonio, TX, USA; dilution: 1:1000), washed, and incubated with a $1: 2000$ dilution of horseradish peroxidase-linked donkey anti-rabbit antibody for $1 \mathrm{~h}$ at room temperature. After washing, protein detection was performed by incubation with Lumi-Light substrate (Roche, Mannheim, Germany). Equal amounts of the loaded samples were confirmed by $\beta$-actin detection with the monoclonal mouse anti-human $\beta$-actin antibody (Sigma-ldrich, Deisenhofen, Germany; clone AC-15). Data on X-ray films were quantified by densitometry.

\section{Statistical analysis}

For statistical analysis, disease stages were defined according to the principles outlined by the UICC (Sobin and Wittekind, 1997) and disease stages I and II were compared with disease stages III and 
IV. Statistical analysis was performed using the SPSS 9.0 software package (SPSS Inc., Chicago, IL, USA). The expression of the different survivin-variants in cancer tissues was compared by the Wilcoxon-test. Correlation between the expression levels of survivin variants and clinicopathological variables was examined using the nonparametric Mann-Whitney-test. A two-tailed $P$-value less than 0.05 was considered to indicate statistical significance.

\section{RESULTS}

\section{Expression of survivin variants}

Expression of survivin and its alternative splice variants (survivin- $\Delta \mathrm{Ex} 3$ and survivin-2B) was detectable in all gastric cancer specimens $(n=30)$, irrespective of their histological types, grades and stages (Figure 1A). Because we had applied cycle numbers for PCR amplification of survivin and GAPDH that did not reach the saturation phase, a densitometric evaluation and comparison of the mRNA levels between different tissue samples was feasible. As shown in Figure 1B, survivin was the predominant transcript variant, whereas only low levels of survivin- $\Delta \mathrm{Ex} 3$ and survivin-2B were observed. The differences of expression between the survivin variants were statistically significant $(P<0.001)$.

Fourteen matched pairs of non-neoplastic and neoplastic gastric tissue samples were compared for their expression of survivin variants. In eight out of 14 non-neoplastic tissue samples, no or barely detectable levels of survivin mRNA levels were observed. Survivin expression in each cancer tissue sample exceeded that of the matched non-neoplastic tissue sample (Figure 2A), the overall expression levels in cancer being significantly higher $(P=0.005)$ when compared to non-neoplastic tissues (Figure 2B). Whereas survivin- $\Delta \mathrm{Ex} 3$ expression did not significantly differ between non-neoplastic and neoplastic tissue samples $(P=0.059)$, survivin$2 \mathrm{~B}$ expression was significantly $(P=0.02)$ elevated in gastric carcinomas (Figure 2B).

\section{Stage-dependent decrease in survivin-2B expression}

Survivin expression has previously been reported to be related to prognosis of cancer patients (Adida et al, 1998, 2000; Kawasaki et al, 1998; Monzo et al, 1999; Swana et al, 1999; Sarela et al, 2000; Kato et al, 2001). Therefore, we analysed the stage-dependent expression of the different survivin variants, comparing low stages (I+II according to UICC (Sobin and Wittekind, 1997)) and advanced stages (III and IV according to UICC (Sobin and Wittekind, 1997)) of gastric cancer. As shown in Figure 3, the expression levels of the anti-apoptotic survivin variants (i.e. survivin and survivin- $\Delta \mathrm{Ex} 3$ ) did not significantly change between low (I+II) and advanced (III+IV) tumour stages. In contrast, a significant $(P=0.033)$ decrease in the expression of the nonanti-apoptotic survivin-2B variant became evident in advanced stages of gastric cancer. To ensure that the stage-dependent decrease of survivin-2B expression was not the result of a

A

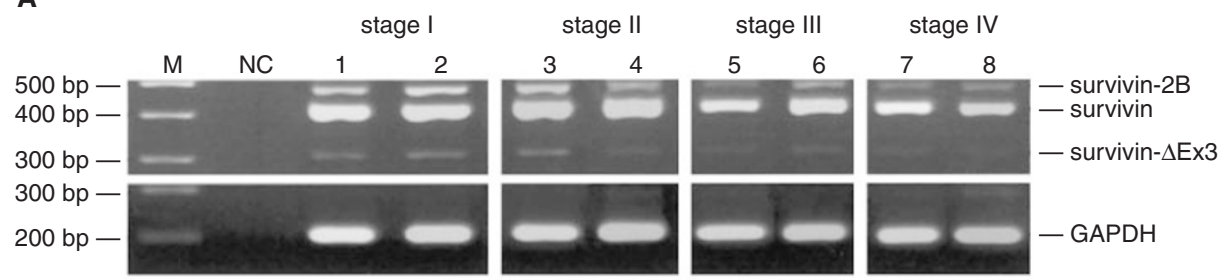

B

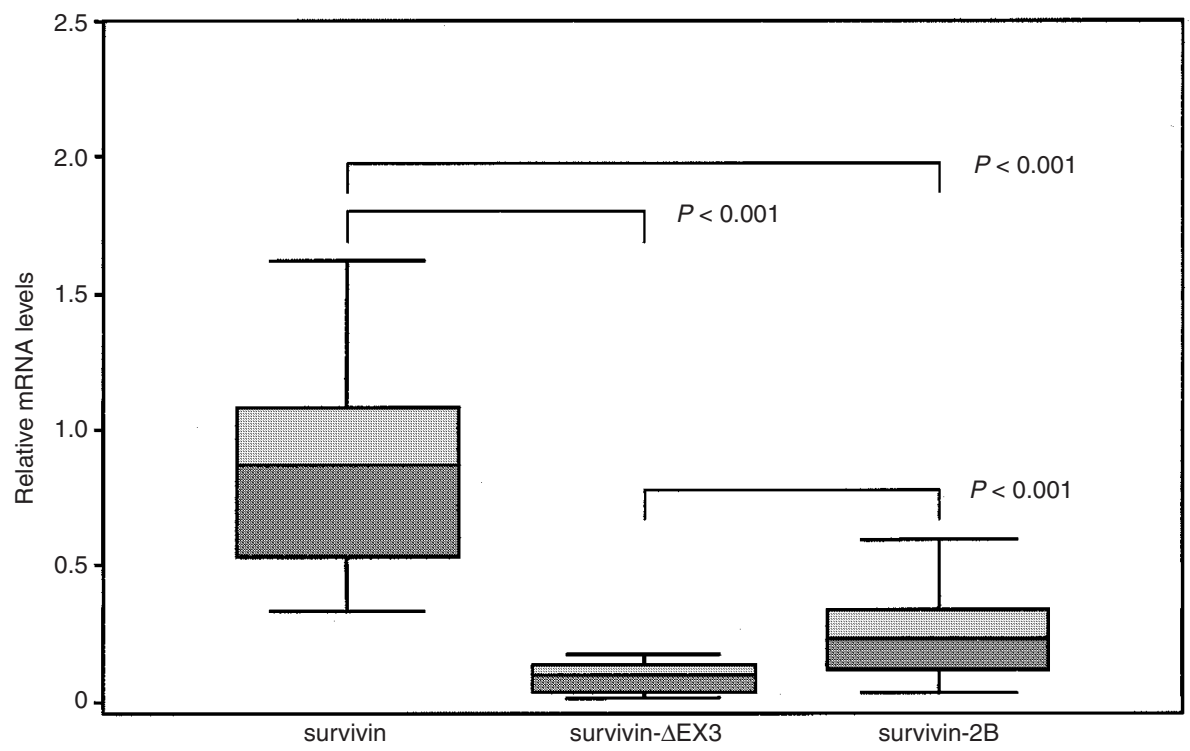

Figure I RT-PCR amplification (A) and relative (GAPDH-normalised) mRNA levels (B) of survivin and its alternative splice variants in gastric cancer. (A) Two $\mu \mathrm{g}$ of total RNA was reversely transcribed and amplified by polymerase chain reaction. PCR-products were electrophoresed and visualised by ethidium bromide staining. Four arbitrarily selected examples of each UICC disease stage are shown. M, molecular weight marker; NC, negative control $\left(\mathrm{H}_{2} \mathrm{O}\right.$ ); survivin (43I bp); survivin-2B (500 bp); survivin- $\Delta$ Ex3 (329 bp). (B) Survivin is the dominant transcript. P-values were calculated by the Wilcoxon-test. 
A

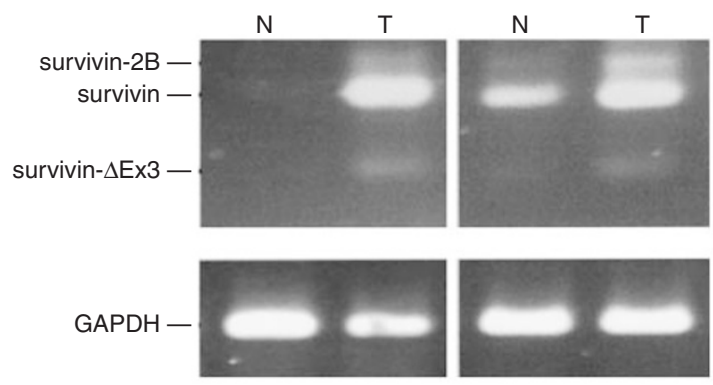

B
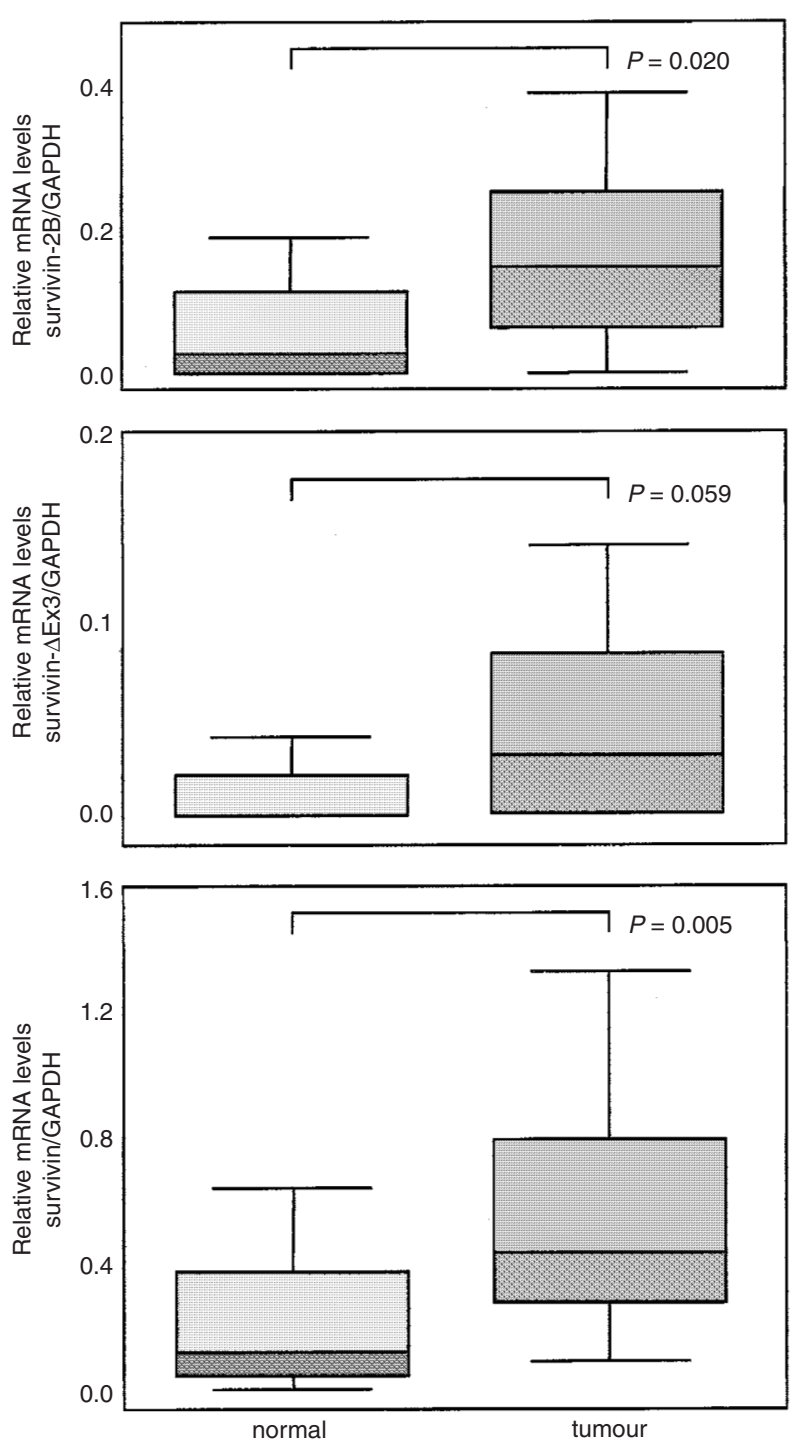

Figure 2 RT-PCR-amplification (A) and relative (GAPDH-normalised) mRNA levels (B) of survivin variants in paired samples of non-neoplastic $(\mathrm{N})$ and neoplastic $(\mathrm{T})$ gastric tissue. (A) In eight out of I 4 non-neoplastic tissue samples, no or barely detectable levels of survivin mRNA levels were observed. In each cancer tissue sample, survivin expression level exceeded that of the corresponding non-neoplastic tissue sample. GAPDH served as internal control. (B) Expression of survivin and survivin-2B - but not survivin- $\Delta \mathrm{E} \times 3$ - are elevated in gastric carcinomas. Two-tailed $P$-values were calculated by the Mann - Whitney-test.
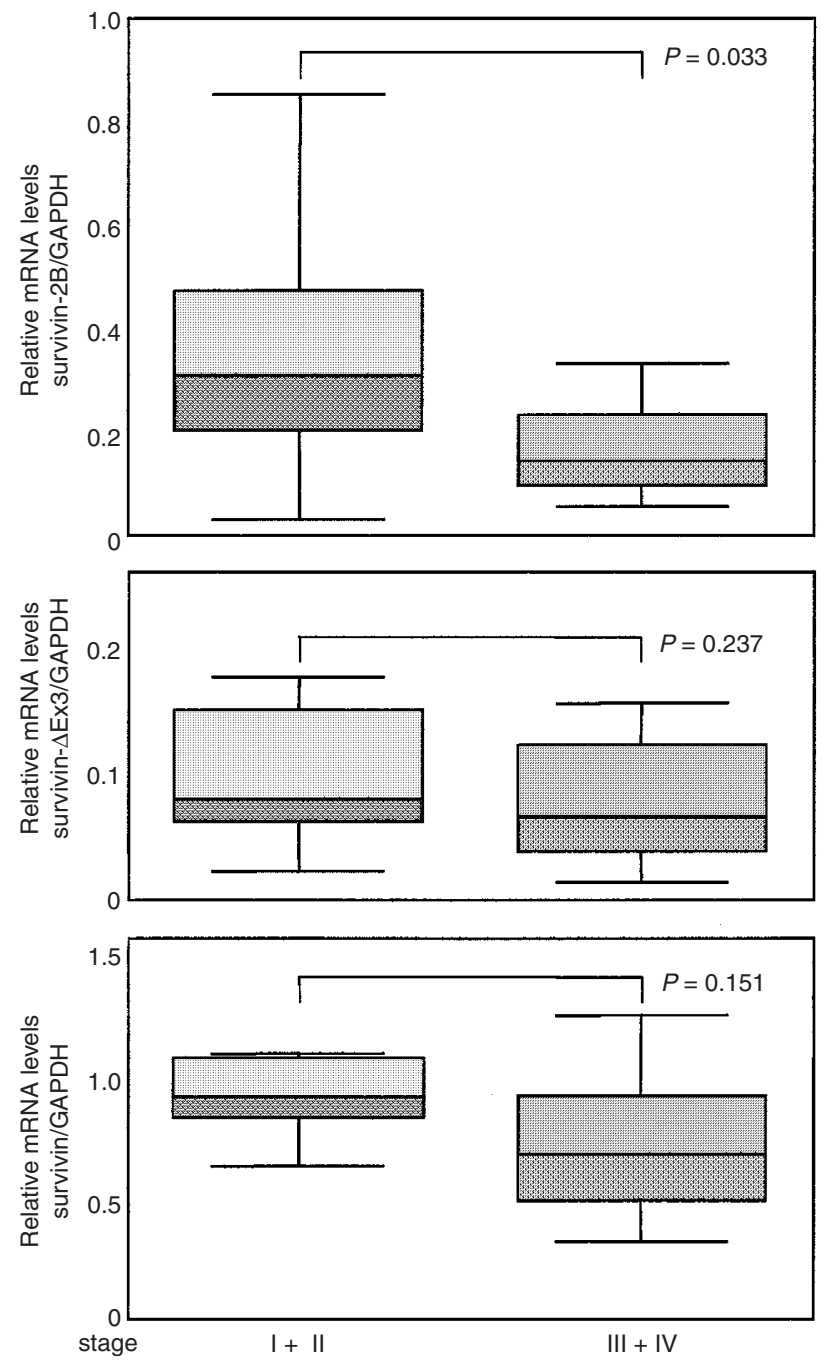

Figure 3 Relative (GAPDH-normalised) mRNA levels of the different survivin variants in gastric carcinomas of different stages. A significant decrease in the expression of survivin-2B is found in advanced disease stages. Two-tailed $P$-values were calculated by the Mann - Whitney-test.

stage-dependent increase of GAPDH transcripts used as an external standard, we additionally calculated the ratios of mRNA levels between survivin- $\Delta \mathrm{Ex} 3$ or survivin- $2 \mathrm{~B}$ on one hand and survivin as an internal standard on the other hand. Because all survivin variants are derived from a common hnRNA precusor pool, these ratios are independent from a possible bias imposed by possible variations of GAPDH expression levels. The difference between these ratios $(P=0.037)$ further confirmed the significant stage-dependent decrease of non-anti-apoptotic survivin-2B (Figure 4).

\section{Correlation between the expression levels of survivin variants and clinicopathological parameters}

To detect a possible correlation between the expression levels of survivin variants and other clinicopathological parameters, the Mann - Whitney-test for nonparametric data was performed. With the exception of the stage-dependent decrease in the expression of survivin-2B (see above), none of the investigated clinicopathological variables showed a statistically significant correlation with the expression levels of survivin and its alternative splice variants (Table 1). 

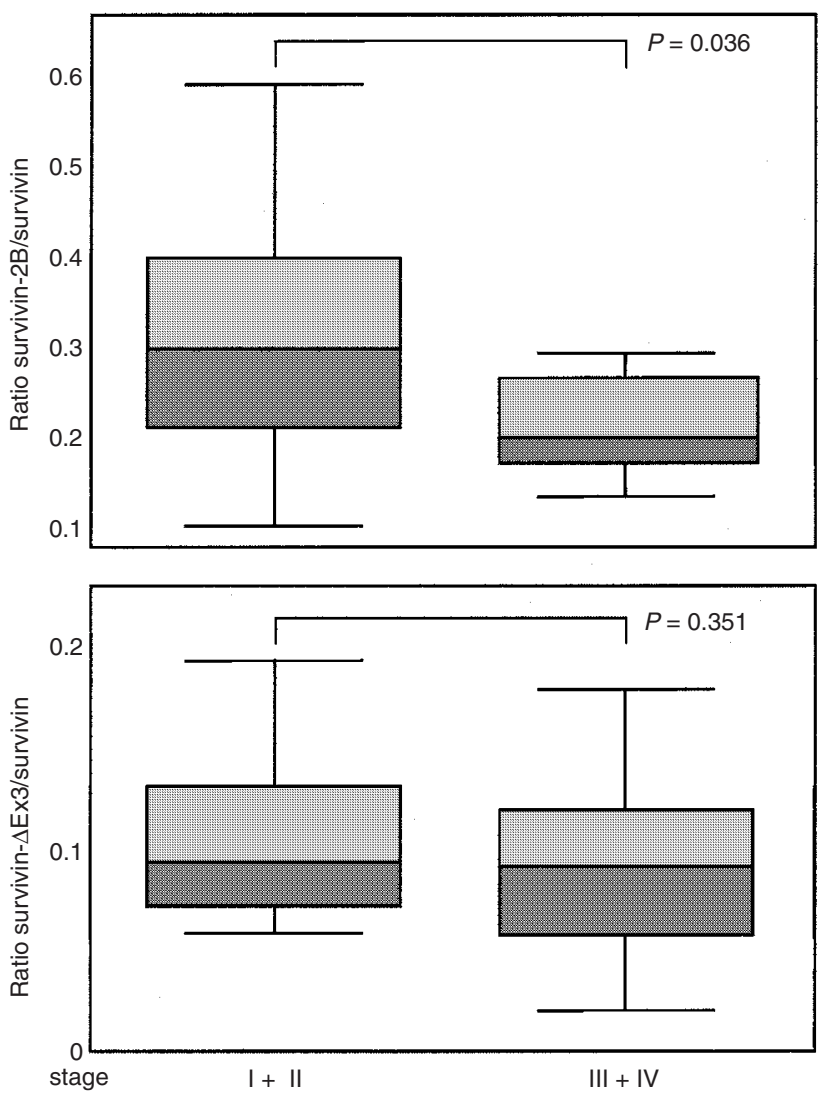

Figure 4 Ratio of relative mRNA levels between the different survivin variants in gastric carcinomas. Significant decrease of the survivin-2B/survivin ratio in advanced $(I I I+I V)$ tumour stages. Two-tailed $P$-values were calculated by the Mann-Whitney-test.

\section{Expression of survivin protein in gastric carcinomas}

Because no antibodies are available so far which recognise survivin$2 \mathrm{~B}$ and survivin- $\Delta \mathrm{Ex} 3$, we could only analyse the expression of survivin protein in four arbitrarily selected gastric carcinoma samples that represent the UICC stages I to IV. All tissue samples showed survivin protein, but no uniform increase of survivin expression became evident in more advanced tumour stages (Figure 5).

\section{DISCUSSION}

In this study, we show that all tissue specimens of gastric cancer express the apoptosis inhibitor survivin and extend a previous report by $\mathrm{Lu}$ et al (1998) on survivin protein expression in $34.5 \%$ of gastric cancer cases to all cases of our study on the mRNA level, using the more sensitive RT-PCR technique. More importantly however, we demonstrate for the first time that the novel splice variants survivin-Ex3 and survivin-2B are expressed in ex vivo tumour samples of gastric cancer.

Recently, survivin has been identified as a structurally and functionally unique member of the inhibitor of apoptosis protein (IAP) family that is highly conserved during evolution (Wenzel et al, 2000) and involved in the regulation of both apoptosis and cell cycle progression ( $\mathrm{Li}$ et al, 1998, 1999). At variance with the ubiquitous distribution of other IAPs in foetal and adult tissues, intensive survivin expression in proliferating foetal tissues contrasts with down-regulation in most differentiated adult tissues (Ambrosini et al, 1997). Most strikingly, however, expression of survivin was found in the most common human cancer types, which might promote both tumour progression and resistance to chemotherapy
Table I Correlation between expression levels of survivin variants and clinicopathological parameters

\begin{tabular}{|c|c|c|c|c|}
\hline \multirow[b]{2}{*}{ Variables } & \multirow{2}{*}{$\begin{array}{l}\text { No. of } \\
\text { patients }\end{array}$} & \multicolumn{3}{|c|}{$P$-value } \\
\hline & & Survivin & Survivin- $\Delta$ Ex3 & Survivin-2B \\
\hline \multicolumn{5}{|l|}{ Stage $(\text { UICC) })^{\mathrm{a}}$} \\
\hline $\begin{array}{l}\text { I+II } \\
\text { III+IV }\end{array}$ & $\begin{array}{l}15 \\
15\end{array}$ & 0.152 & 0.237 & 0.033 \\
\hline \multicolumn{5}{|c|}{ Histological grade } \\
\hline $\begin{array}{l}\mathrm{Gl}^{\mathrm{b}}+\mathrm{G} 2 \\
\mathrm{G} 3+\mathrm{G} 4^{\mathrm{b}}\end{array}$ & $\begin{array}{r}9 \\
21\end{array}$ & 0.428 & 0.982 & 0.067 \\
\hline \multicolumn{5}{|l|}{ Histological type } \\
\hline Intestinal & 16 & 0.645 & 0.272 & 0.231 \\
\hline Diffuse & 11 & & & \\
\hline Mixed & c & & & \\
\hline \multicolumn{5}{|c|}{ Lymphatic vessel invasion } \\
\hline Positive & 20 & 0.860 & 0.509 & 0.895 \\
\hline Negative & 10 & & & \\
\hline \multicolumn{5}{|c|}{ Blood vessel invasion } \\
\hline Positive & 8 & 0.399 & 0.223 & 0.281 \\
\hline Negative & 22 & & & \\
\hline \multicolumn{5}{|c|}{ Helicobacter pylori infection } \\
\hline Positive & 14 & 0.561 & 0.739 & 0.430 \\
\hline Negative & 16 & & & \\
\hline \multicolumn{5}{|c|}{ Chronic inflammation $^{\mathrm{d}}$} \\
\hline Present & 19 & 0.098 & 0.237 & 0.333 \\
\hline Absent & 11 & & & \\
\hline \multicolumn{5}{|l|}{ Age } \\
\hline$\leqslant 65$ years & 16 & 0.183 & 0.135 & 0.135 \\
\hline$>65$ years & 14 & & & \\
\hline \multicolumn{5}{|l|}{ Sex } \\
\hline Female & 10 & 0.428 & 0.895 & 0.598 \\
\hline Male & 20 & & & \\
\hline
\end{tabular}

${ }^{a}$ Depth of infiltration: $\mathrm{pTI}: n=2 ; \mathrm{pT2}: n=19 ; \mathrm{pT3}: n=8 ; \mathrm{pT}: \mathrm{n=1}$. Lymph node involvement: $\mathrm{pNO}: n=5$; $\mathrm{pNI}: n=14$; pN2: $n=5$; $\mathrm{pN} 3: n=6$. Distant metastasis: M0: $n=2 ; M I: n=5$. ${ }^{b}$ Only one case. 'Not included in statistical analysis due to the

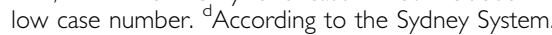

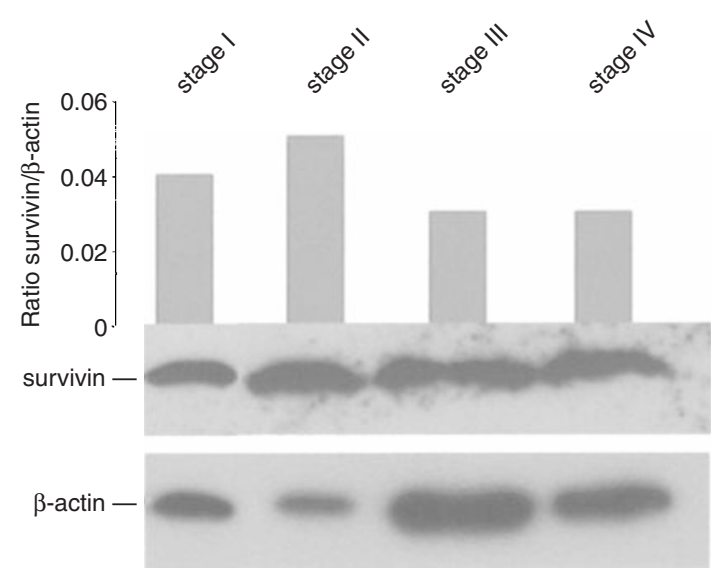

Figure 5 Expression of survivin protein in gastric carcinomas. One hundred $\mu \mathrm{g}$ protein of each tumour sample were assessed for survivin and $\beta$ actin expression. Grey bars reflect the relative expression levels of survivin as measured by densitometry.

and irradiation. The molecular mechanisms by which survivin inhibits apoptosis are still under investigation. In vitro experiments have shown that survivin binds and inhibits the cell death effector proteases caspase-3 and caspase-7 (Tamm et al, 1998; Shin et al, 2001). Moreover, survivin was found to associate specifically with 
centromeres, microtubules of the mitotic spindle and Cdk4, thereby supposedly regulating the progression of foetal and neoplastic cells through mitosis (Li et al, 1998; Suzuki et al, 2000; Uren et al, 2000; Wheatley et al, 2001).

The complexity of survivin actions is further augmented by the expression of two functionally divergent alternative splice variants, i.e. survivin- $\Delta \mathrm{Ex} 3$ and survivin-2B. As recently demonstrated by our group (Mahotka et al, 1999), both splice variants exhibit structural alterations of their single BIR domain. Despite these structural modifications, the anti-apoptotic potential of survivin$\Delta \mathrm{Ex} 3$ seems to be largely preserved, whereas survivin-2B exhibited a loss of anti-apoptotic properties and, therefore, might act as a naturally occurring antagonist of survivin (Mahotka et al, 1999). Although further experimental work is necessary to elucidate the functional properties of the different splice variants in more detail, first clues to the involvement of survivin- $\Delta \mathrm{Ex} 3$ and survivin-2B in the progression of gastric carcinoma can be derived from our present study.

In this study, we found mRNA expression of the anti-apoptotic variants survivin and survivin- $\Delta \mathrm{Ex} 3$ in all major histological types of gastric carcinomas, irrespective of their grading and staging. Analysis of matched pairs of non-neoplastic and neoplastic tissue samples revealed expression of both survivin variants in nonneoplastic gastric tissues and a significant increase in survivin but not survivin- $\Delta \mathrm{Ex} 3-\mathrm{mRNA}$ expression levels in cancer tissue Especially the use of more sensitive RT-PCR has demonstrated survivin expression in other non-neoplastic tissues as well, including normal lung samples, endothelial cells and lymphocytes (Monzo et al, 1999; Tran et al, 1999; Kornacker et al, 2001). The low levels of survivin mRNA in non-neoplastic tissues argue against the assumption that increased survivin levels in gastric cancer might only be due to an increased proportion of lymphocytes. Our observations, therefore, further confirmed the ubiquitous increase of survivin expression in human cancer as previously reported for other tumour types as well (Adida et al, 1998, 2000; Kawasaki et al, 1998; Lu et al, 1998; Monzo et al, 1999; Swana et al, 1999; Sarela et al, 2000; Kato et al, 2001).

Increased survivin mRNA or protein expression has previously been reported to be a prognostic indicator of tumour progression in different types of human cancer (Adida et al, 1998, 2000; Kawasaki et al, 1998; Monzo et al, 1999; Swana et al, 1999; Sarela et al, 2000; Kato et al, 2001). The densitometric quantification of mRNA levels performed in our study, however, did not reveal a correlation

\section{REFERENCES}

Adida C, Berrebi D, Peuchmaur M, Reyes-Mugica M, Altieri DC (1998) Antiapoptosis gene, survivin, and prognosis of neuroblastoma. Lancet 351: $882-883$

Adida C, Haioun C, Gaulard P, Lepage E, Morel P, Briere J, Dombret H, Reyes F, Diebold J, Gisselbrecht C, Salles G, Altieri DC, Molina T) (2000) Prognostic significance of survivin expression in diffuse large B-cell lymphomas. Blood 96: $1921-1925$

Ambrosini G, Adida C, Altieri DC (1997) A novel anti-apoptosis gene, survivin, expressed in cancer and lymphoma. Nat Med 3: 917-921

Chao DT, Korsmeyer SJ (1998) BCL-2 family: regulators of cell death. Ann Rev Immunol 16: 395-419

Chomczynski P, Sacchi N (1987) Single-step method of RNA isolation by acid guanidinium thiocyanate- phenol-chloroform extraction. Anal Biochem 162: $156-159$

Conway EM, Pollefeyt S, Cornelissen J, DeBaere I, Steiner-Mosonyi M, Ong K, Baens M, Collen D, Schuh AC (2000) Three differentially expressed survivin cDNA variants encode proteins with distinct antiapoptotic functions. Blood 95: 1435-1442

Crook NE, Clem RJ, Miller LK (1993) An apoptosis-inhibiting baculovirus gene with a zinc finger-like motif. J Virol 67: 2168-2174

Deveraux QL, Reed JC (1999) IAP family proteins suppressors of apoptosis. Genes Dev 13: 239-252 between expression levels of survivin and the histological types, grades or stages of gastric carcinomas. This observation was further supported by Western blot analysis of arbitrarily selected gastric carcinomas, and is in accordance with a previous immunohistochemical analysis of gastric cancer ( $\mathrm{Lu}$ et al, 1998), which failed to reveal a significant correlation between survivin expression and tumour depth, lymph node metastasis or disease stage. Increased expression of anti-apoptotic survivin, therefore, might be an early event in gastric carcinogenesis, as has formerly been suggested for survivin in other tumour types as well (Grossman et al, 1999).

In accordance with our observations in renal carcinoma cell lines (Mahotka et al, 1999), the mRNA levels of survivin-2B in gastric carcinomas were significantly lower than those of survivin. Moreover, the expression of survivin-2B significantly decreased in advanced stages of gastric cancer. These low levels of survivin-2B expression, however, might not reflect the actual significance of survivin-2B for the progression of gastric cancer. Thus, the stagedependent downregulation of survivin-2B might affect the susceptibility to apoptosis induction in two ways. The decrease of survivin-2B transcripts could permit the generation of more antiapoptotic survivin variants (i.e. survivin and survivin- $\Delta \mathrm{Ex} 3$ ), because all survivin variants originate from a common pool of a hnRNA percusor. Parallel to the decrease of survivin-2B, the anti-apoptotic effects of survivin could become even more predominant, if survivin-2B actually acts as a natural antagonist as suggested by Islam et al (2000).

In conclusion, our study presents first data on the in vivo expression of novel survivin splice variants in gastric carcinomas. Expression of survivin-2B - but not of survivin and survivin$\Delta \mathrm{Ex} 3$ - was shown to be related to tumour progression in gastric cancer. These findings indicate for the first time that alternative splice variants of survivin may be involved in the fine tuning of survivin actions in gastric carcinomas.

\section{ACKNOWLEDGEMENTS}

We thank Michael Ringler and Martina Bellack for technical assistance. The results of this work are part of the MD thesis of Andreas Krieg. This work was supported by a grant from the Deutsche Forschungsgemeinschaft (DFG).

Dixon MF, Genta RM, Yardley JH, Correa P (1996) Classification and grading of gastritis. The updated Sydney System. International Workshop on the Histopathology of Gastritis, Houston 1994. Am J Surg Pathol 20: $1161-1181$

Fadeel B, Orrenius S, Zhivotovsky B (2000) The most unkindest cut of all: on the multiple roles of mammalian caspases. Leukemia 14: 1514-1525

Grossman D, McNiff JM, Li F, Altieri DC (1999) Expression and targeting of the apoptosis inhibitor, survivin, in human melanoma. J Invest Dermatol 113: $1076-1081$

Islam A, Kageyama H, Hashizume K, Kaneko Y, Nakagawara A (2000) Role of survivin, whose gene is mapped to $17 \mathrm{q} 25$, in human neuroblastoma and identification of a novel dominant-negative isoform, survivin-beta/2B Med Pediatr Oncol 35: 550-553

Kato J, Kuwabara Y, Mitani M, Shinoda N, Sato A, Toyama T, Mitsui A, Nishiwaki T, Moriyama S, Kudo J, Fujii Y (2001) Expression of survivin in esophageal cancer: correlation with the prognosis and response to chemotherapy. Int J Cancer 95: 92-95

Kawasaki H, Altieri DC, Lu CD, Toyoda M, Tenjo T, Tanigawa N (1998) Inhibition of apoptosis by survivin predicts shorter survival rates in colorectal cancer. Cancer Res 58: 5071-5074 
Kornacker M, Verneris MR, Kornacker B, Scheffold C, Negrin RS (2001) Survivin expression correlates with apoptosis resistance after lymphocyte activation and is found preferentially in memory $\mathrm{T}$ cells. Immunol Lett 76: $169-173$

LaCasse EC, Baird S, Korneluk RG, MacKenzie AE (1998) The inhibitors of apoptosis (IAPs) and their emerging role in cancer. Oncogene 17: $3247-$ 3259

Li F, Ackermann EJ, Bennett CF, Rothermel AL, Plescia J, Tognin S, Villa A, Marchisio PC, Altieri DC (1999) Pleiotropic cell-division defects and apoptosis induced by interference with survivin function. Nat Cell Biol 1: $461-466$

Li F, Ambrosini G, Chu EY, Plescia J, Tognin S, Marchisio PC, Altieri DC (1998) Control of apoptosis and mitotic spindle checkpoint by survivin. Nature 396: $580-584$

Lu CD, Altieri DC, Tanigawa N (1998) Expression of a novel antiapoptosis gene, survivin, correlated with tumor cell apoptosis and p53 accumulation in gastric carcinomas. Cancer Res 58: $1808-1812$

Mahotka C, Wenzel M, Springer E, Gabbert HE, Gerharz CD (1999) Survivin-deltaEx3 and survivin-2B: two novel splice variants of the apoptosis inhibitor survivin with different antiapoptotic properties. Cancer Res 59: $6097-6102$

Monzo M, Rosell R, Felip E, Astudillo J, Sanchez JJ, Maestre J, Martin C, Font A, Barnadas A, Abad A (1999) A novel anti-apoptosis gene: Re-expression of survivin messenger RNA as a prognosis marker in non-small-cell lung cancers. J Clin Oncol 17: 2100-2104

Roy N, Deveraux QL, Takahashi R, Salvesen GS, Reed JC (1997) The c-IAP-1 and c-IAP-2 proteins are direct inhibitors of specific caspases. EMBO J 16: 6914-6925

Rudin CM, Thompson CB (1997) Apoptosis and disease: regulation and clinical relevance of programmed cell death. Ann Rev Med 48: 267-281

Sarela AI, Macadam RC, Farmery SM, Markham AF, Guillou PJ (2000) Expression of the antiapoptosis gene, survivin, predicts death from recurrent colorectal carcinoma. Gut 46: 645-650

Shin S, Sung BJ, Cho YS, Kim HJ, Ha NC, Hwang JI, Chung CW, Jung YK, $\mathrm{Oh} \mathrm{BH}$ (2001) An anti-apoptotic protein human survivin is a direct inhibitor of caspase-3 and -7. Biochemistry 40: 1117-1123

Skoufias DA, Mollinari C, Lacroix FB, Margolis RL (2000) Human survivin is a kinetochore-associated passenger protein. J Cell Biol 151: 1575-1582
Sobin LH, Wittekind Ch (1997) TNM classification of malignant tumors 5th ed Wiley-Liss, New York: Chickerten Weinheim

Suzuki A, Hayashida M, Ito T, Kawano H, Nakano T, Miura M, Akahane K, Shiraki K (2000) Survivin initiates cell cycle entry by the competitive interaction with Cdk4/p16(INK4a) and Cdk2/cyclin E complex activation. Oncogene 19: $3225-3234$

Swana HS, Grossman D, Anthony JN, Weiss RM, Altieri DC (1999) Tumor content of the antiapoptosis molecule survivin and recurrence of bladder cancer [letter]. N Engl J Med 341: $452-453$

Tamm I, Wang Y, Sausville E, Scudiero DA, Vigna N, Oltersdorf T, Reed JC (1998) IAP-family protein survivin inhibits caspase activity and apoptosis induced by Fas (CD95), Bax, caspases, and anticancer drugs. Cancer Res 58: $5315-5320$

Thompson CB (1995) Apoptosis in the pathogenesis and treatment of disease. Science 267: $1456-1462$

Tran J, Rak J, Sheehan C, Saibil SD, LaCasse E, Korneluk RG, Kerbel RS (1999) Marked induction of the IAP family antiapoptotic proteins survivin and XIAP by VEGF in vascular endothelial cells. Biochem Biophys Res Commun 264: $781-788$

Uren AG, Wong L, Pakusch M, Fowler KJ, Burrows FJ, Vaux DL, Choo KH (2000) Survivin and the inner centromere protein INCENP show similar cell-cycle localization and gene knockout phenotype. Curr Biol 10: $1319-1328$

Watanabe H, Jass JR, Sobin LH (1998) Histological typing of oesophageal and gastric tumours. WHO International Classification of Tumours 2 nd ed Springer-Verlag, Berlin, Heidelberg, New York

Wenzel M, Mahotka C, Krieg A, Bachmann A, Schmitt M, Gabbert HE, Gerharz CD (2000) Novel survivin-related members of the inhibitor of apoptosis (IAP) family [letter]. Cell Death Differ 7: 682-683

Wheatley SP, Carvalho A, Vagnarelli P, Earnshaw WC (2001) INCENP is required for proper targeting of survivin to the centromeres and the anaphase spindle during mitosis. Curr Biol 11: 886-890

Zaman GJ, Conway EM (2000) The elusive factor Xa receptor: failure to detect transcripts that correspond to the published sequence of EPR-1. Blood 96: $145-148$ 